\title{
Os Três Momentos Pedagógicos em consonância com a Abordagem Temática ou Conceitual: uma reflexão a partir das pesquisas com olhar para o Ensino de Ciências da Natureza
}

\author{
The three pedagogical moments in keeping with the thematic approach or conceptual: a \\ reflection from surveys looking at the Natural Science Education \\ Marines Verônica Ferreira ${ }^{1}$, Catiane Mazocco Paniz ${ }^{2}$ e Cristiane Muenchen ${ }^{3}$ \\ ${ }^{1}$ Mestranda do Programa de Pós graduação Educação em Ciências: química da vida e saúde. \\ Universidade Federal de Santa Maria, RS, Brasil \\ marinesmvf@hotmail.com \\ ${ }^{2}$ Doutoranda do Programa de Pós graduação em Educação em Ciências: química da vida e saúde \\ Professora do Instituto Federal de Santa Maria, RS, Brasil \\ catiane.paniz@iffarroupilha.edu.br \\ ${ }^{3}$ Professora do departamento de Física e dos programas de Pós graduação em Educação em Ciências e Educação \\ Matemática e Ensino de Física., Universidade Federal de Santa Maria, RS, Brasil \\ crismuenchen@yahoo.com.br
}

\begin{abstract}
Resumo
O presente trabalho tem por objetivo apresentar os resultados obtidos a partir de uma análise efetuada nos artigos selecionados do I ao IX Encontro Nacional de Pesquisa em Educação em Ciências (ENPECs), que fazem menção à dinâmica dos Três Momentos Pedagógicos (3MP) conhecida como: Problematização Inicial (PI), Organização do Conhecimento (OC) e Aplicação do Conhecimento (AC), na qual se investigou se os (3MP) vem sendo utilizados em consonância com a perspectiva curricular da Abordagem Temática ou da Abordagem Conceitual. Utilizando a Análise Textual Discursiva como metodologia de análise, foi possível perceber que os 3MP estão sendo desenvolvidos tanto como metodologia de sala de aula, como estruturante de currículos, em consonância com abordagem temática.nh Também se analisou em quais níveis de ensino e regiões do país vêm sendo disseminada a dinâmica, constatando-se que a disseminação se dá de forma mais acentuada na região sul, e os trabalhos são desenvolvidos, em sua maioria, no contexto do Ensino Médio.
\end{abstract}

Palavras-chave: Três momentos pedagógicos. Abordagem temática. Abordagem Conceitual.

\begin{abstract}
This study aims to present the results obtained from an analysis performed on selected articles from I to IX National Research Meeting in Science Education (ENPECs) that mention the dynamics of Pedagogical Three Moments (3MP) known as: Curriculum Home (PI), Knowledge Organization (OC) and Knowledge Application ( $A C)$, in which he investigated the (3MP) has been used in line with the curricular perspective of Thematic Approach Using Text Analysis Discourse analysis as a methodology, it was revealed that the $3 M P$ are being developed both as a classroom methodology as structuring curricula in line with thematic approach or Conceptual Approach. Also analyzed in which education levels and regions of the country coming spreading dynamics and the spread occurs more sharply in the south, and the works are developed, mostly in the context of high school.
\end{abstract}

Keywords: Three pedagogical moments. Thematic approach. Conceptual approach. 


\section{Introdução e Referencial Teórico}

Segundo Muenchen e Delizoicov (2010), a dinâmica conhecida como Três Momentos Pedagógicos (3MP) passou a ser disseminada no final da década de 80 . Isso porque, os livros "Metodologia do Ensino de Ciências" (DELIZOICOV e ANGOTTI, 1989) e "Física" (DELIZOICOV e ANGOTTI, 1990), que tratam sobre o tema, foram distribuídos nas escolas públicas de nível médio do Brasil, por meio de um programa do INEP/MEC. Além disso, esses materiais passaram a constar nas referências bibliográficas de cursos de licenciatura da área de Ciências, de programas de pós-graduação, em concursos públicos para a carreira de magistério e cursos de formação continuada de docentes.

Essa dinâmica, abordada inicialmente por Delizoicov (1982), ao promover a transposição da concepção de Paulo Freire para o espaço da educação, é baseada na perspectiva da abordagem temática e pode ser caracterizada da seguinte maneira para o trabalho pedagógico de sala de aula: no primeiro momento pedagógico, que equivale à Problematização Inicial (PI), procura-se tratar de situações que estejam associadas à realidade dos alunos para que, deste modo, eles se sintam desafiados a expor as suas opiniões sobre os questionamentos que estão sendo realizados e notem a necessidade de adquirir outros conhecimentos que ainda não possuem.

Já no segundo momento, que corresponde à Organização do Conhecimento (OC), são estudados, sob a mediação do docente, os conhecimentos científicos necessários para que os educandos consigam entender o assunto/tema que está sendo trabalhado, bem como as PI efetuadas anteriormente. E, por fim, na Aplicação do Conhecimento (AC), que diz respeito ao terceiro momento pedagógico, são retomados os questionamentos realizados na PI, a fim de analisar os conhecimentos que foram incorporados pelos alunos no decorrer da aula. Além disso, neste momento, podem ser efetuados também outros questionamentos relacionados ao conhecimento científico que foi trabalhado na OC.

Em pesquisas realizadas por Muenchen (2010), Muenchen, Delizoicov (2009, 2014),
Araujo et al (2012) e Ferreira et al (2014), os autores perceberam que os 3MP são utilizados como metodologia de sala de aula, sendo por isso usados como forma para explicar conceitos científicos. Conforme Muenchen (2010), esse aspecto pode estar relacionado ao fato tanto de o livro Metodologia do Ensino de Ciências como no livro Física, utilizados por muitos docentes, não trazerem a discussão dos 3MP como estruturantes de currículos, sendo que, nestas obras, os 3MP são usados no desenvolvimento de trabalhos de sala de aula.

Conforme Muenchen (2010) e Muenchen e Delizoicov (2012), os 3MP também podem ser utilizados como estruturantes de currículos. Desta forma, os conhecimentos científicos são abordados na compreensão de situações que apresentam contradições sociais significativas para a realidade dos educandos, considerando que essas contradições surgem a partir da investigação da realidade da comunidade na qual a escola está inserida.

Nesta dinâmica a construção do conhecimento também ocorre a partir dos conhecimentos prévios que os estudantes possuem sobre os questionamentos que lhes estão sendo propostos, podendo essa ser entendida, então, como ponto de partida para a construção do conhecimento científico dos alunos. Em consonância com que foi acima mencionado, Freire (1987) destaca que: [...] "o educador já não é o que apenas educa, mas o que, enquanto educa, é educado, em diálogo com o educando que, ao ser educado, também o educa. Ambos, assim, se tornam sujeitos do processo em que crescem juntos e em que os "argumentos de autoridade" já, não valem" [...] (p. 39).

Além disso, através da dinâmica dos $3 \mathrm{MP}$, o discente se torna capaz de associar o conhecimento que está sendo construído por meio das problematizações de sua realidade, as quais contribuem também para motivá-lo quanto à oralidade, uma vez que ela provoca certa inquietação nos alunos ${ }_{\llcorner}$por gerar discussões a partir do contexto em que eles estão inseridos. Posto isso, em consonância com Freire, se propõe repensar a relação entre currículo e a comunidade escolar, pois esse é estruturado com base nos temas significativos para aquela realidade. 
De acordo com Delizoicov, Angotti e Pernambuco (2011), o aspecto mais significativo da proposta de transposição da perspectiva freireana para a educação escolar é a forma de estruturar o currículo, de maneira a torná-lo mais relevante e dinâmico. O planejamento das atividades educativas e sua implementação, incluindo a seleção de conteúdo, rompe com o paradigma curricular tradicional, baseado na abordagem conceitual. Para Delizoicov et al., a abordagem temática constitui-se em: Perspectiva curricular cuja lógica de organização é estruturada com base em temas com os quais são selecionados os conteúdos de ensino das disciplinas. Nessa abordagem, a conceituação científica da programação é subordinada ao tema (2011, p.189).

Já a abordagem conceitual é compreendida como: Perspectiva curricular cuja lógica de organização é estruturada pelos conceitos científicos, com base nos quais se selecionam os conteúdos de ensino (2011, p.190).

A abordagem conceitual dá ênfase ao conceito científico, enquanto a abordagem temática enfatiza o conceito científico como meio para a compreensão de um tema.

Ainda, Muenchen e Delizoicov (2013) perceberam através da análise de materiais didáticos produzidos pelos professores em suas práticas docentes, e nos diversos documentos referentes aos projetos desenvolvidos pelos formadores destes professores, que alguns educadores compreendem melhor a dinâmica didático-pedagógica dos 3MP, e conseguem realizar problematizações em suas práticas pedagógicas. Já os professores que não passaram por novos processos formativos e se mantiveram em contato com os 3MP somente pelos livros didáticos, ficaram apenas no nível de perguntas e da abordagem conceitual.

Em estudo realizado por Muenchen e Delizoicov (2010), com foco na investigação de como e com que frequência os 3MP têm sido utilizados nos artigos pertencentes à região de Santa Maria, publicados no I e V Encontro Nacional de Pesquisa em Ciências (ENPECs), os autores puderam notar um crescimento da utilização de tal dinâmica na região supracitada. No entanto, salientam que os $3 \mathrm{MP}$ não se concentram em apenas uma região do Brasil e sugerem um estudo mais amplo a respeito do uso dessa dinâmica. Deste modo, este trabalho procura investigar se os 3MP estão sendo discutidos, por pesquisadores da área de Educação em Ciências, em consonância com abordagem temática ou com a abordagem conceitual. Além disso, avalia-se em quais regiões do país a dinâmica está sendo disseminada e em quais níveis de ensino.

\section{Metodologia}

Com o propósito de compreender se os 3MP estão sendo disseminados em consonância com Abordagem Temática, e em que níveis de ensino e regiões estão sendo desenvolvidos, foi efetuado um estudo nas atas digitalizadas do I ao IX ENPEC, selecionando os artigos que tratam sobre a dinâmica dos $3 \mathrm{MP}$, cujo critério usado para elegê-los foi o de constar pelo menos uma das seguintes palavras-chave: Três Momentos Pedagógicos, Momentos Pedagógicos e Problematização Inicial.

Ao todo foram analisados 5.836 trabalhos e selecionados 72 , que tratam sobre os 3MP. Após esse processo, foi realizada a leitura de cada um dos artigos selecionados para verificar se apresentam um detalhadamente quanto ao uso da dinâmica dos 3MP. Ao longo deste procedimento, notou-se que 39 dos 72 trabalhos, apresentam detalhadamente no uso da dinâmica dos 3MP, diferindo, assim dos outros 33 que se restringem ao destaque da utilização da dinâmica, sendo, por isso, retirados da investigação. A figura 1 representa o resumo da seleção por edição dos respectivos artigos que compõe a referida análise documental. 


\begin{tabular}{|c|c|c|c|}
\hline Ano/Edição & $\begin{array}{c}\text { Total de trabalhos } \\
\text { publicados }\end{array}$ & $\begin{array}{c}\text { Total de Trabalhos } \\
\text { selecionados pelas } \\
\text { palavras-chave }\end{array}$ & $\begin{array}{c}\text { Total de Trabalhos } \\
\text { que detalham como os } \\
\text { 3MP são empregados }\end{array}$ \\
\hline 1997/ I ENPEC & 138 & 3 & 1 \\
\hline $1999 /$ II ENPEC & 163 & 3 & 0 \\
\hline $2001 /$ IIIENPEC & 233 & 5 & 6 \\
\hline 2003 IV ENPEC & 451 & 13 & 10 \\
\hline $2005 /$ V ENPEC & 739 & 14 & 4 \\
\hline $2007 /$ VI ENPEC & 669 & 5 & 9 \\
\hline $2009 /$ VII ENPEC & 723 & 10 & 7 \\
\hline $2011 /$ VIII ENEPC & 1235 & 11 & 39 \\
\hline $2013 /$ IX ENPEC & 1485 & 72 & \\
\hline
\end{tabular}

Figura 1 - Número de Trabalhos por ENPEC (1997 a 2013)

Através de uma leitura mais pormenorizada, verificou-se em que níveis de ensino os trabalhos foram desenvolvidos. Com relação aos níveis de ensino, os estudos utilizados nesta análise foram organizados em: Ensino Fundamental, Ensino Médio, Ensino Superior, Formação Continuada, EJA e Proeja. Por meio desta leitura também foram verificadas as regiões em que os 3MP estão sendo disseminados.
No que confere à análise dos 3MP em consonância com perspectiva de Abordagem Temática ou Abordagem Conceitual, foram retirados da pesquisa 4 trabalhos, por abordarem cursos de formação de professores, uma vez que o foco da presente pesquisa é a disseminação dos 3MP no contexto de sala de aula. Assim, restaram 35 trabalhos para análise. A seguir, a figura 2 ilustra pesquisas que detalharam o uso dos 3MP no contexto da sala de aula.

\begin{tabular}{|c|c|c|}
\hline TÍTULO DO TRABALHO & AUTOR/ANO & ENCONTRO \\
\hline $\begin{array}{l}\text { 1- Uma proposta metodológica para o ensino de } \\
\text { ácidos e bases numa abordagem } \\
\text { problematizadora }\end{array}$ & $\begin{array}{l}\text { Chaves \& Pimetel } \\
\text { (1997) }\end{array}$ & I ENPEC \\
\hline $\begin{array}{l}\text { 2- Reprodução Humana: abordagem histórica } \\
\text { na formação dos professores de Biologia }\end{array}$ & $\begin{array}{l}\text { Slongo \& Delizoicov } \\
\text { (2001) }\end{array}$ & III ENPEC \\
\hline $\begin{array}{l}\text { 3- Cadeia Alimentar: modelos e modelizações } \\
\text { no ensino de Ciências Naturais }\end{array}$ & $\begin{array}{l}\text { Oliveira, Paz, Abegg } \\
\quad \& \text { Silva (2003) }\end{array}$ & IV ENPEC \\
\hline $\begin{array}{l}\text { 4- Ciências e tecnologia nas séries iniciais do } \\
\text { ensino fundamental: das políticas públicas a } \\
\text { investigação-ação nas aulas de ciências }\end{array}$ & $\begin{array}{l}\text { Abegg, Filho \& } \\
\text { Bastos (2003) }\end{array}$ & IV ENPEC \\
\hline $\begin{array}{l}5 \text { Função afim e conceitos unificadores: o } \\
\text { ensino de matemática e Física numa } \\
\text { perspectiva conceitual e unificadora }\end{array}$ & $\begin{array}{l}\text { Lopes, Angotti \& } \\
\text { Moretti (2003) }\end{array}$ & IV ENPEC \\
\hline $\begin{array}{l}\text { 6- Um estudo sobre o uso de atividade didática } \\
\text { com texto de divulgação cientifica em aulas } \\
\text { de física }\end{array}$ & $\begin{array}{l}\text { Terrazzan, Lunardi \& } \\
\text { Hernandes (2003) }\end{array}$ & IV ENPEC \\
\hline $\begin{array}{l}\text { 7- Calor e temperatura: uma intervenção em } \\
\text { sala de aula }\end{array}$ & $\begin{array}{l}\text { Kahnlein \& Peduzzi } \\
\quad \text { (2003) }\end{array}$ & IV ENPEC \\
\hline
\end{tabular}




\begin{tabular}{|c|c|c|}
\hline TÍTULO DO TRABALHO & AUTOR/ANO & ENCONTRO \\
\hline $\begin{array}{l}\text { 8- Desvelando objetos técnicos com tecnologias } \\
\text { de comunicação e informação }\end{array}$ & $\begin{array}{l}\text { Silva, Angotti \& Mion } \\
\text { (2003) }\end{array}$ & IV ENPEC \\
\hline $\begin{array}{l}\text { 9- Unidades Didáticas interdisciplinares: } \\
\text { possibilidades e desafios }\end{array}$ & $\begin{array}{l}\text { Goulart \& Freitas } \\
\text { (2005) }\end{array}$ & V ENPEC \\
\hline $\begin{array}{l}\text { 10- Educação Científica e tecnológica: a } \\
\text { incorporação da curiosidade epistemológica } \\
\text { no ensino de Física }\end{array}$ & Maia \& Mion (2005) & V ENPEC \\
\hline $\begin{array}{l}\text { 11- Enfoque CTS: configurações curriculares } \\
\text { sensíveis a temas contemporâneos }\end{array}$ & $\begin{array}{l}\text { Muenchen, Griebeler, } \\
\text { Santini, Forgiarini, } \\
\text { Strieder, Hunsche, } \\
\text { Gehlen \& Auler (2005) }\end{array}$ & V ENPEC \\
\hline $\begin{array}{l}\text { 12- A utilização do referencial teórico de Paulo } \\
\text { Freire na compreensão de um processo de } \\
\text { acompanhamento da prática pedagógica de } \\
\text { professores de física }\end{array}$ & $\begin{array}{r}\text { Sauerwein \& } \\
\text { Terrazzan (2005) }\end{array}$ & V ENPEC \\
\hline $\begin{array}{l}\text { 13- Ampliando o conceito de tempo através da } \\
\text { inserção da teoria da relatividade restrita no } \\
\text { ensino médio }\end{array}$ & $\begin{array}{l}\text { Karam, Coimbra \& } \\
\text { Cruz (2005) }\end{array}$ & $\mathrm{V}$ ENPEC \\
\hline $\begin{array}{l}\text { 14- Compatibilidade entre competências e } \\
\text { habilidades em atividades didáticas } \\
\text { produzidas por professores em processo de } \\
\text { formação compartilhada }\end{array}$ & $\begin{array}{c}\text { Weber, Metke, } \\
\text { Somavilla \& Terrazzan } \\
\text { (2005) }\end{array}$ & V ENPEC \\
\hline $\begin{array}{l}\text { 15- Dificuldades dos Licenciandos em adotar } \\
\text { uma abordagem verde em seus projetos de } \\
\text { ensino de química }\end{array}$ & Melo \& Villane (2005) & $\mathrm{V}$ ENPEC \\
\hline $\begin{array}{l}\text { 16- Ensino de física com equipamentos agrícolas } \\
\text { numa escola Agrotécnica }\end{array}$ & $\begin{array}{l}\text { Santini \& Terrazzan } \\
\quad(2005)\end{array}$ & V ENPEC \\
\hline $\begin{array}{l}\text { 17- O ensino de física através de temas: buscando } \\
\text { e aperfeiçoando a prática pedagógica no } \\
\text { grupo de trabalho de professores de física } \\
\text { (GTPF/NEC UFSM) }\end{array}$ & $\begin{array}{l}\text { Santini, Terrazzan, } \\
\text { Hoffmann } \\
\text { \& Metke (2005) }\end{array}$ & V ENPEC \\
\hline $\begin{array}{l}\text { 18- O uso de equipamentos agrícolas para o } \\
\text { ensino de Física }\end{array}$ & $\begin{array}{l}\text { Santini \& Terrazzan } \\
\quad(2005)\end{array}$ & V ENPEC \\
\hline $\begin{array}{l}\text { 19- Avaliando uma proposta de ensino através } \\
\text { de temas sociais e prática CTS: o motor à } \\
\text { combustão }\end{array}$ & $\begin{array}{l}\text { Souza \& Alencar } \\
\quad(2007)\end{array}$ & VI ENPEC \\
\hline $\begin{array}{l}\text { 20- A importância da problematização na } \\
\text { construção e na aquisição do conhecimento } \\
\text { científico pelo sujeito }\end{array}$ & $\begin{array}{l}\text { Honorato \& Mion } \\
\qquad(2009)\end{array}$ & VII ENPEC \\
\hline
\end{tabular}




\begin{tabular}{|c|c|c|}
\hline TÍTULO DO TRABALHO & AUTOR/ANO & ENCONTRO \\
\hline $\begin{array}{l}\text { 21- Ensino de química no PROEJA: integrando o } \\
\text { espaço virtual de aprendizagem às ações de } \\
\text { sala de aula }\end{array}$ & $\begin{array}{l}\text { Souza, Reis \& } \\
\text { Linhares (2009) }\end{array}$ & VII ENPEC \\
\hline $\begin{array}{l}\text { 22- Educação problematizadora no ensino de } \\
\text { Computação Quântica: um caminho para a } \\
\text { Alfabetização Científica e Tecnológica }\end{array}$ & $\begin{array}{l}\text { Santos, Ferrari, } \\
\text { Almeida (2011) }\end{array}$ & VIII ENPEC \\
\hline $\begin{array}{l}\text { 23- Problematização no ensino de Ciências: uma } \\
\text { análise da Situação de Estudo }\end{array}$ & $\begin{array}{l}\text { Halmenschlager } \\
\text { (2011) }\end{array}$ & VIII ENPEC \\
\hline $\begin{array}{l}\text { 24- Abordagem temática no currículo de ciências: } \\
\text { a perspectiva ético-crítica na concepção de } \\
\text { lixo como condição humana }\end{array}$ & $\begin{array}{l}\text { Furlan, Ricci, } \\
\text { Gomes\& } \\
\text { Silva (2011) }\end{array}$ & VIII ENPEC \\
\hline $\begin{array}{l}\text { 25- A contextualização e a organização dialógica } \\
\text { no ensino de botânica na formação inicial de } \\
\text { professores de biologia para superação de } \\
\text { dificuldades deste ensino }\end{array}$ & $\begin{array}{l}\text { Prado, Alves, Enrione } \\
\quad \text { \& Silva (2011) }\end{array}$ & VIII ENPEC \\
\hline $\begin{array}{l}\text { 26- CTSA na formação do professor e } \\
\text { pesquisador e a tradição latino-americana }\end{array}$ & Mion (2011) & VIII ENPEC \\
\hline $\begin{array}{l}\text { 27- Abordagem Temática no Ensino de Física: } \\
\text { relações entre a perspectiva Vygotskyana e os } \\
\text { Momentos Pedagógico }\end{array}$ & $\begin{array}{l}\text { Miguel, Correa \& } \\
\text { Gehlen (2011) }\end{array}$ & VIII ENPEC \\
\hline $\begin{array}{l}\text { 28- Contextualizando regionalmente o ensino de } \\
\text { física: a revolução quebra quilos }\end{array}$ & $\begin{array}{l}\text { Santos, Silva } \\
\text { \& Silveira (2011) }\end{array}$ & VIII ENPEC \\
\hline $\begin{array}{l}\text { 29- Análise da prática de um professor de física } \\
\text { que busca o reconhecimento e legitimação } \\
\text { pelo aluno da cultura própria e da cultura } \\
\text { cientifica }\end{array}$ & $\begin{array}{l}\text { Rosa, Carvalho \& } \\
\text { Lopes (2011) }\end{array}$ & VIII ENPEC \\
\hline $\begin{array}{l}\text { 30- O Ensino de Matemática e Astronomia na } \\
\text { EJA por meio da Abordagem Temática }\end{array}$ & $\begin{array}{l}\text { Avelar, Junior, } \\
\text { Langhl } \\
\text { \& Gehlen (2011) }\end{array}$ & VIII ENPEC \\
\hline 31- O ensino de ciências e a alimentação escolar & $\begin{array}{l}\text { Fagundes \& Pinheiro } \\
\text { (2013) }\end{array}$ & IX ENPEC \\
\hline $\begin{array}{l}\text { 32- A contextualização na Abordagem Temática } \\
\text { Freireana e no Ensino de Ciências por } \\
\text { Investigação }\end{array}$ & $\begin{array}{l}\text { Solino \& Gehlen } \\
\quad \text { (2013) }\end{array}$ & IX ENPEC \\
\hline $\begin{array}{l}\text { 33- Desafios e potencialidades na elaboração de } \\
\text { uma proposta de ensino com base em temas }\end{array}$ & $\begin{array}{l}\text { Filho, Neto, Silva, } \\
\text { Junior, Araújo, Bardella, } \\
\text { Coimbra \& Hunsche } \\
\text { (2013) }\end{array}$ & IX ENPEC \\
\hline
\end{tabular}




\begin{tabular}{|c|c|c|}
\hline TÍTULO DO TRABALHO & AUTOR/ANO & ENCONTRO \\
\hline $\begin{array}{l}\text { 34- Inserção das Redes Sociais na Aprendizagem } \\
\text { de Conceitos Físicos: Análise da opinião dos } \\
\text { Estudantes sobre Atividades em Ambientes } \\
\text { Virtuais }\end{array}$ & $\begin{array}{l}\text { Polonine, Ambrósio } \\
\text { \& Coelho (2013) }\end{array}$ & IX ENPEC \\
\hline $\begin{array}{l}\text { 35- A construção de um terrário como recurso à } \\
\text { interdisciplinaridade no ensino de ciências: } \\
\text { uma proposta fundamentada nos momentos } \\
\text { pedagógicos e na situação de estudo. }\end{array}$ & $\begin{array}{l}\text { Sawitzki \& Pereira } \\
\text { (2013) }\end{array}$ & IX ENPEC \\
\hline
\end{tabular}

Figura 2 - Ilustração das pesquisas realizadas em sala de aula que detalham o uso dos 3MP

Após a delimitação da amostra, foram construídas as fichas de leituras de cada trabalho para, então, serem realizadas as devidas constatações. No que diz respeito à análise dos dados, além da distribuição por nível de ensino e regiões do país, utilizou-se a Análise Textual Discursiva (MORAES E GALIAZZI, 2007), delimitando categorias a priori, ou seja, 3MP em consonância com a Abordagem Conceitual ou 3MP em consonância com Abordagem Temática. A seguir, apresenta-se a análise dos dados.

\section{Análise e Discussão dos dados}

\subsection{Distribuição por Nível de Ensino}

A primeira constatação realizada, a partir da leitura dos artigos supracitados, foi quanto aos níveis de ensino nos quais a dinâmica dos 3MP estava sendo utilizada.

Na figura 3, pode-se visualizar a distribuição dos 3MP por nível de ensino.

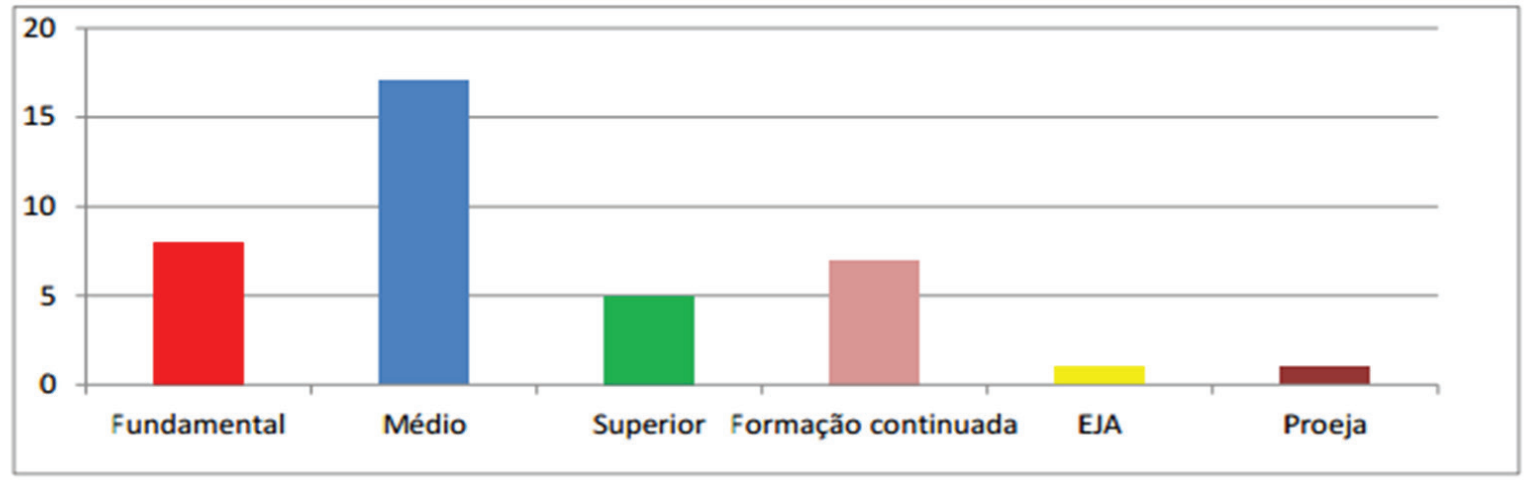

Figura 3 -: Distribuição por Nível de Ensino

Através desta organização, foi possível notar que 17 dos artigos analisados usam a dinâmica dos 3MP no Ensino Médio, totalizando um percentual de 43,5\%. Já no Ensino Fundamental, 8 trabalhos empregam esta dinâmica, o que equivale a $21 \%$ do total de artigos publicados nas edições investigadas. Tais dados diferenciam-se, assim, do Ensino Superior, já que 5 trabalhos usam os $3 \mathrm{MP}$, equivalendo a 13,1\% do total. Na Formação Continuada, observou-se que 7 artigos utilizam a dinâmica, representando, deste modo, um percentual de $18,4 \%$ do total das publicações que integram o corpus dessa pesquisa. E, finalmente, no Proeja e EJA, foi encontrado apenas 1 artigo em cada modalidade, o que corresponde a 2,5\% em cada nível.

A maior incidência na utilização dos 3MP no Ensino Médio pode estar relacionada à distribuição do livro Física (DELIZOICOV; ANGOTTI, 1990) às escolas de Ensino Médio por meio do Programa de Melhoria e Expansão do Ensino Médio (MEC) (MUENCHEN e DELIZOICOV, 2014). Já a segunda maior ocorrência, ou seja, Ensino Fundamental, pode estar relacionada à distribuição do livro Metodologia do Ensino de Ciências (DELIZOICOV, ANGOTTI e PERNANBUCO, 2011) nas escolas e nas Secretárias Municipais de Educação de todos os estados brasileiros no ano 
de 1994 e 1995, pelo Programa Biblioteca do Professor (PNBP) (MUENCHEN, 2010; MUENCHEN e DELIZOICOV, 2012). Ressaltase, ainda, que o percentual vinculado à formação continuada, esteja relacionada a estes livros fazerem parte, de acordo com Muenchen (2010), de bibliografias destinadas a cursos de formação continuada de professores, nos quais os 3MP são empregados. Ademais, a autora aponta as obras como parte de ementas de disciplinas dos cursos de Licenciatura da área de Ciências da Natureza e de programas de pós-graduação com foco no Ensino de Ciências, o que pode ter contribuído para a dissipação da dinâmica neste âmbito.

\section{2- Distribuição por Regiões}

No que tange à análise referente as regiões, procurou-se fazer um agrupamento dos 39 artigos que apresentam detalhadamente o uso dos 3MP, considerando as cinco regiões brasileiras. Ao longo deste processo foi possível perceber que um mesmo trabalho estava, às vezes, relacionado a mais de uma instituição/região. Assim, na presente pesquisa, alguns artigos foram contabilizados para mais de uma instituição, quando estes se referiam a diferentes locais, o que justifica o número de dados apresentados na figura 4 .

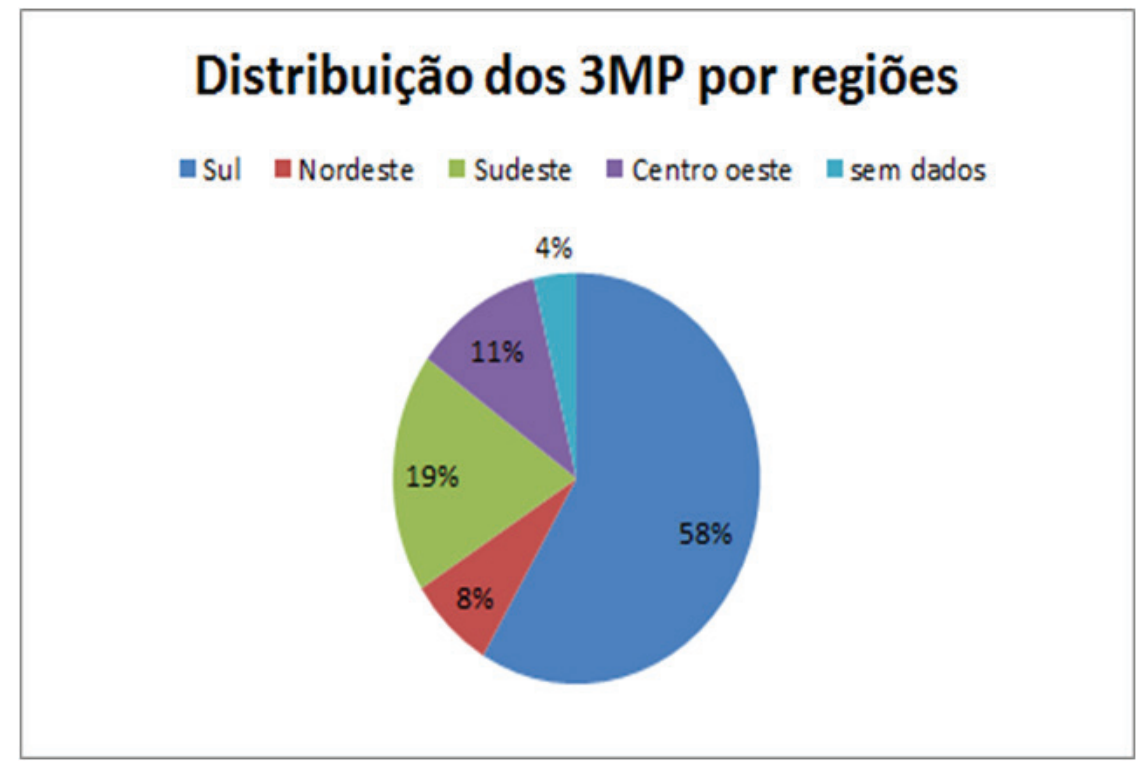

Figura 4 - Distribuição dos 3MP por regiões

A partir desses resultados, pode-se notar que $58,4 \%$ das instituições pertencem à região sul do país. Já 18, 8\% fazem parte da região Sudeste, o que difere da região Centro-Oeste, em que se obteve um percentual de $11,3 \%$. Quanto à região Nordeste, foram agrupadas $7,5 \%$ das instituições. Na região Norte, por seu turno, não foi encontrada nenhuma instituição dentre 39 trabalhos selecionados. Além disso, 3,8\% não apresentaram a identificação.

Nesse passo, a maior disseminação dos 3MP aconteceu na região Sul. Tal constatação se deve, possivelmente, ao fato de alguns dos idealizadores dessa dinâmica atuar como docentes em Universidades Federais da região e terem orientado em programas de pós graduação. Desta forma, o número de docentes que trabalham com esta perspectiva vem aumentando, pois muitos de seus orientandos e ex-orientados também atuam em universidades na região Sul e disseminam esta dinâmica tanto em ambientes de sala de aula como nas pesquisas que desenvolvem.

Quanto ao resultado da disseminação da dinâmica dos 3MP ser mais expressivo nas regiões Sul e Sudeste, importa destacar que esse pôde ter influência quanto ao uso das obras "Física e Metodologia do Ensino de Ciências", como referências nos concursos públicos promovidos pelas Secretarias de Educação para o magistério, conforme pesquisa realizada por Muenchen e Delizoicov (2014). 


\section{3- Utilização dos $3 \mathrm{MP}$ em consonância com abordagem conceitual e abordagem temática}

Dentre os trabalhos analisados que detalharam o uso dos 3MP, procurou-se identificar se esta dinâmica vem sendo desenvolvida a partir da abordagem conceitual ou a partir da abordagem temática (Delizoicov, Angotti e Pernambuco, 2011).

Quanto aos 3MP desenvolvidos em sintonia com a perspectiva da Abordagem Conceitual, constatou-se que as pesquisas $(1,2$, $3,5,6,7,9,12,13,14,16,17,18,20,21,25,28,29$, 34 e 35) são desenvolvidas com o objetivo de se trabalhar um conceito científico, conforme exemplo destacado no trabalho desenvolvido por Chaves e Pimentel (1997, s/p.): “os momentos foram usados em atividades para o ensino do conteúdo Ácidos e Bases por envolver alguns dos conceitos fundamentais em química e por se adequar à programação da professora regente". A partir do trecho citado, percebe-se que a utilização dos 3MP está vinculada a um conteúdo que faz parte da ementa da disciplina de Química, sendo, desta forma, utilizado como metodologia de sala de aula. No entanto, esta perspectiva contribui para possibilitar a discussão e o diálogo com os alunos, por isso, considera-se um avanço nessa área, por oportunizar ao aluno o diálogo, sendo evidenciado no trecho a seguir: Sabemos que existem hortênsias brancas, rosadas, lilases e azuis. Sabemos também que, as vezes, ao longo do tempo, hortênsias rosadas se tornam azuis e vice-versa. Por que será que isto acontece? Se quisermos obter apenas hortênsias azuis ou apenas hortênsias rosadas o que devemos fazer? (CHAVES, PIMENTEL, 1997, s/p.)

Outro exemplo da utilização dos 3MP na perspectiva da abordagem conceitual é visto no trabalho realizado por Oliveira et al. (2003), em que se analisou uma sequência didática. Nesse caso foi possível perceber também que a estruturação das aulas se deu por meio da utilização dos 3MP como metodologia de trabalho de sala de aula, partindo de um conceito científico. Observa-se que o desenvolvimento da aula ocorreu com base apenas em conceitos do livro didático, não considerando os conhecimentos prévios dos alunos sobre o referido assunto. Desta forma, não favoreceu ao aluno a exposição de seus conhecimentos, ficando atrelado apenas ao conceito que o livro didático apresenta.

A situação didática a ser analisada compõem um total de 4 aulas sendo que na primeira a professora regente distribuiu diversos livros didáticos de $1^{\mathrm{a}}$ a $4^{\mathrm{a}}$ série e solicitou que os alunos fizessem uma pesquisa sobre Cadeia Alimentar. Em grupo os alunos localizaram nos livros o assunto e copiaram as informações para seus cadernos, formando um pequeno texto (OLIVEIRA et al., 2003, p. 6).

Diferentemente do artigo de Chaves e Pimentel (1997), o trabalho analisado por Oliveira et al (2003), quanto à problematização inicial, se restringiu a uma pesquisa de conceitos sobre a cadeia alimentar apresentados nos livros didáticos. Desta forma, não houve a valorização do aluno como sujeito ativo no processo de ensino e aprendizagem, estando em consonância ao que Freire chama de educação bancária.

Notou-se também que os 3MP, como metodologia para trabalhar conceitos, vem sendo desenvolvidos no contexto do ensino superior, como exemplo, tem-se o trabalho de Lopes, Angotti e Moretti (2003) que utilizou os 3MP para tratar do conceito de função no ensino de matemática e física.

Tanto a escolha quanto à disposição das atividades foi estabelecida com o objetivo de disponibilizar uma construção gradual do conceito de função afim e propiciar um espaço para a 'problematização inicial' acerca desse conceito através de situações-problema lançadas ao grupo para discussão, buscando identificar as noções informais que os alunos já possuíam a respeito. Nesse momento são enfocadas situações diversas, ligadas ou não à Matemática, procurando dar dimensões intra e extradisciplinares ao conceito de função, através de abordagens diferenciadas (p.8-9).

Foi possível identificar que o uso dos 3MP numa perspectiva conceitual também ocorreu de forma interdisciplinar para abordar conceitos de desmatamento, poluição e preservação dos animais nas séries iniciais do Ensino Fundamental: É preciso lembrar que os Momentos Pedagógicos foram propostos pelos autores para "ensinar" conteúdos de Ciência (Física, Química, Biologia) e que no nosso caso, 
utilizamos os pressupostos teóricos dos mesmos para diferentes áreas do conhecimento (Geografia, História, Matemática, Português) (FREITAS, GOULART, 2005, p. 5 - 6).

Desta forma, salienta-se ainda que o trabalho destaca como objetivo abordagem de conceitos, abordagem conceitual (Delizoicov, Angotti e Pernambuco, 2011), porém, mesmo nesta perspectiva, existe a preocupação das autoras quanto ao desenvolvimento de atitudes em relação ao trabalho coletivo e a conscientização ambiental, a partir das problematizações iniciais destacadas:

Vocês já ouviram falar sobre desmatamento (suas consequências para os animais, para o ar)? O que vocês sabem sobre poluição (da água e do ar)? Quais as formas de se poluir a água e o ar (esgoto, lixo, agrotóxicos, resíduos de indústrias, fumaça). Quais as consequências da poluição (morte de peixes e de outros animais, contaminação dos alimentos e da água que bebemos, destruição da vegetação, destruição da camada de ozônio)? (FREITAS, GOULART, 2005, p. 17).

Em consonância com o trabalho anterior, tem-se a pesquisa de Sauerwein e Terrazzan (2005) que utilizaram os 3MP para a compreensão de conceitos de física moderna e contemporânea, mas com a preocupação de transformar as percepções dos sujeitos no âmbito cognitivo através do processo dialógico.

O processo dialógico se dá na medida em que os sujeitos envolvidos no processo educativo dialogam sobre a sua realidade vivenciada. A tarefa dos investigadores/equipe de investigadores é problematizar as situações destacadas dessa realidade a partir do seu estudo preliminar, visando as transformações. Transformações estas que poderiam ser caracterizadas em dois níveis: o primeiro se daria sobre as percepções dessa realidade e o segundo se daria sobre os possíveis mecanismos de ação para efetivá-las. $(2005$, p.3)

No que confere aos 3MP utilizados a partir de um tema, destaca-se que os conceitos científicos são abordados para compreensão do tema. Sob esta perspectiva, os alunos passam a ser sujeitos ativos no processo, pois seus conhecimentos são valorizados e a partir deles se dá a construção dos conhecimentos científicos. Nesta perspectiva estão os trabalhos $(4,8,10,11$,
$15,19,22,23,24,26,27,30,31,32$ e 33). Como exemplo, destaca-se o trabalho sobre o seguinte tema: "Usinas Elétricas, do funcionamento às suas implicações", e teve o intuito de possibilitar a discussão e a reflexão sobre as diversas formas de produção de energia elétrica, tema relevante naquele momento:

Este foi escolhido por tratar de algo que tem sido sinônimo de grandes repercussões na mídia, momento em que os apagões tem sido cada vez mais frequentes nos grandes centros urbanos e a busca por fontes alternativas de energia tem recebido estímulos governamentais. (FILHO, et al, 2013, p.3).

Por meio desse trabalho, notou-se que os conhecimentos científicos foram abordados de forma a contribuir para a compreensão do tema. Ademais, de forma expressiva, houve a preocupação em potencializar a capacidade de análise crítica do aluno, como afirma o trecho a seguir:

É importante destacar que a proposta busca, não somente tratar de conceitos da Física, mas também refletir sobre os pontos sociais, históricos e ambientais que circundam cada parte do processo, uma vez que o objetivo é que, ao final das aulas, os alunos possam ser críticos e atuantes acerca do tema. Ou seja, ao tratar de questões como: "Qual usina é mais viável?"; "Qual causa menos impactos ambientais?"; "Qual é a mais barata e rentável?", possam opinar com argumentos mais sólidos, justificados e lúcidos, compreendidos graças aos conceitos trabalhados em sala de aula e em laboratório, sobre questões polêmicas envolvendo a construção das usinas. (FILHO, et al, 2013, p. 3).

Outro exemplo de uso dos 3MP em consonância com abordagem temática é a pesquisa desenvolvida por Abegg, Filho e Bastos, tendo como tema da aula/produto tecnológico a caixa de leite Tetra Pak, sendo que a partir desta abordaram:

[...] conceitos científicos (isolamento térmico, radiação térmica, temperatura, por exemplo) e tecnológicos (processos UHT de conservação do leite, embalagem Tetra Pak, composição das diversas camadas da caixa longa vida, por exemplo) como processo e produto da ciência e tecnologia. Dessa forma, lançamos mão de um produto tecnológico (caixa de leite longa 
vida) estudando-o não só seu processo de fabricação, mas também sua função social, numa perspectiva CTS, no âmbito de um projeto de produção e destino de lixo na escola nas aulas de CN\&T (ABBEG, FILHO, BASTOS, 2003, p.9)

No trabalho citado anteriormente, os pesquisadores propuseram ainda aos alunos que, ao final, precisam articular formas de reutilização das caixas de leite Tetra Pak, evitando assim que fossem enviadas para os lixões.

Ainda, na perspectiva dos 3MP em consonância com a abordagem temática destacase a investigação intitulada "A Contextualização na Abordagem Temática Freireana e no Ensino de Ciências por investigação". A realização deste trabalho foi além daqueles anteriormente citados, sendo que este foi articulado a partir dos problemas sociais vivenciados pelos discentes, através da realização de uma pesquisa em que buscaram conhecer tais situações.

A primeira refere-se à seleção do tema a ser trabalhado em sala de aula, em que foi realizada a primeira etapa da Investigação Temática (FREIRE, 1987), denominada de Levantamento Preliminar. Ao fazer o estudo da realidade local, por meio de fotografias do entorno da cidade e do bairro onde se localizava a escola, manchetes de jornais online, dados estatísticos do município e conversas informais com as coordenadoras da escola, foi constatado um problema que representa uma contradição social vivenciada pelos moradores de Itabuna (BA): a questão da poluição das águas de um rio desta cidade, conhecido como Rio Cachoeira. A partir dessa situação problemática, emergiu o tema, em discussão com o grupo GEATEC/UESC, denominado de "Rio Cachoeira: que água é essa?". O problema (tema) selecionado representa uma situação-limite (SILVA, 2004), uma vez que a poluição do Rio Cachoeira muitas vezes é visto pela comunidade de Itabunense como uma fatalidade, favorecendo uma visão acrítica dos alunos sobre essa questão. [...]alguns conteúdos de Física, Química, Biologia e Educação Ambiental foram selecionados para desenvolver a temática em sala de aula, assim como foram planejadas 10 aulas, sendo três delas contendo atividades experimentais investigativas de conhecimento físico[...] (SOLINO, GEHLEN, 2013, p. 4)
O uso dos 3MP para se trabalhar a temática Rio Cachoeira possibilita ao educador, através do diálogo como os educandos, apreender os conhecimentos prévios deles, para então, introduzir os conhecimentos científicos necessários para a compreensão do tema de forma mais abrangente. Conforme Freire (1987), os conhecimentos prévios dos educandos precisam ser considerados e valorizados no processo de aprendizagem, pois, assim, haverá maior interesse por parte do educando em pesquisar sobre o tema para contribuir na compreensão dos conceitos abordados na aula.

\section{Considerações Finais}

Este trabalho foi desenvolvido a partir da análise das publicações entre o I e o IX Encontro Nacional de Pesquisa em Ciências ENPEC's. Por meio desta pesquisa, pôde ser percebido que, os $3 \mathrm{MP}$ vêm sendo disseminados de forma mais intensa na região Sul. Constata-se que é possível ser este um fator de influência, já que o número de docentes que utilizam essa dinâmica em suas práticas influenciaram outros docentes, durante seus processos formativos. Além disso, alguns dos idealizadores dessa dinâmica desenvolvem atividades de pesquisa e docência em instituição da região Sul do Brasil. Também por orientarem pesquisas de docentes que atuam nesta região, os quais hoje também disseminam essa dinâmica.

Com relação aos níveis de Ensino que os 3MP estão sendo usados, percebeu-se um número de trabalhos maior desenvolvido no contexto do Ensino Médio. Tal fato pode ser decorrente da distribuição da obra "Física" às escolas de Ensino Médio. Desta forma, um grande número de professores do Ensino Médio tiveram contato com os 3MP.

Quanto ao uso dos 3MP em consonância a uma abordagem conceitual ou abordagem temática, notou-se que têm sido desenvolvidas pesquisas nos dois sentidos, pois dos 35 trabalhos, 20 apresentaram uma abordagem conceitual e 15 abordagem temática. Deste modo, os 3MP estão sendo utilizados tanto como metodologia para se trabalhar um conceito científico, como para trabalhar um tema. Entretanto, foi possível notar um avanço nos 
trabalhos que usam os 3MP como metodologia para abordar um conceito que possibilita ao aluno sua participação nas discussões. E, em relação ao uso dos $3 \mathrm{MP}$ como estruturante de currículos, ou seja, desenvolvido a partir de um tema, foi possível perceber que esse também vem sendo desenvolvido em diferentes perspectivas, como: no desenvolvimento de práticas didáticopedagógicas, para ser desenvolvida a consciência crítica do aluno, sobre o desenvolvimento da Ciência e da Tecnologia e o papel da sociedade na tomada de decisão, pensando, enfim, em práticas pedagógicas que o aluno tem papel ativo, sendo ele o sujeito do processo de aprendizagem. Nesta perspectiva de ensino são realizadas investigações para chegar a situações que sejam relevantes ao educando e, desta forma, construir um currículo que faça sentido a ele.

Como continuidade desta pesquisa, torna-se relevante aprofundar as perspectivas da abordagem temática desenvolvidas em consonância com os 3MP, através do contato com os autores para analisar como os currículos escolares estão sendo estruturados quando adotam a perspectiva da abordagem temática.

\section{Referências}

ARAUJO, L. B., NIEMEYER, J., MAGOGA, T., MUENCHEN, C. A Concepção Freireana e os Três Momentos Pedagógicos: Alguns Resultados dos Trabalhos Apresentados nos Encontros Nacionais de Pesquisa em Ensino de Física (EPEF). VI Seminário Nacional Diálogos com Paulo Freire, 2012, Santa Maria/RS.

CHAVES, M. H., PIMENTEL, N. Uma proposta metodológica para o ensino de ácidos e bases numa abordagem problematizadora. Atas do I Encontro Nacional de Pesquisa em Educação em Ciências (ENPEC), Águas de Lindóia/ São Paulo, 1997.

DELIZOICOV, D. Concepção problematizadora do ensino de ciências na educação formal. Dissertação de mestrado. São Paulo: IFUSP/FEUSP, 1982.
DELIZOICOV, D.; ANGOTTI, J. A. Física. São Paulo: Cortez, 1990.

DELIZOICOV, D.; ANGOTTI, J. A. Metodologia do ensino de ciências. São Paulo: Cortez, 1989.

DELIZOICOV, D.; ANGOTTI, J.A.; PERNAMBUCO, M.C.A. Ensino de Ciências: Fundamentos e Métodos. São Paulo: Cortez, 2011.

FERREIRA, M.V.; NIEMEYER, J.; PANIZ, C.M.; MUENCHEN, C. A utilização da Problematização Inicial no Ensino de Ciências: um olhar a partir dos Encontros Nacionais de Pesquisa em Educação em Ciências (ENPECs). In. VIII Seminário Nacional: Diálogos com Paulo Freire - Por Uma Pedagogia dos Direitos Humanos. Bento Gonçalves/RS, 2014.

FILHO et al. Desafios e potencialidades na elaboração de uma proposta de ensino com base em temas. IX Encontro Nacional em educação em Ciências (ENPEC), Águas de Lindóia/São Paulo, 2013.

FREIRE, P. Pedagogia do Oprimido. $17^{a}$ ed. Rio de Janeiro: Paz e Terra, 1987.

GOULART, S. F.; FREITAS, D. S. Unidades Didáticas interdisciplinares: possibilidades e desafios. V Encontro Nacional em Educação em Ciências (ENPEC), Bauru/São Paulo, 2005.

LOPES, ANGOTTI \& MORETTI. Função afim e conceitos unificadores: o ensino de matemática e Física numa perspectiva conceitual e unificadora. IV Encontro Nacional de Pesquisa em Educação em Ciências (ENPEC), Bauru/São Paulo, 2003.

MORAES, R.; GALIAZZI, M. do C. Análise Textual Discursiva. Ijuí: Ed. Unijuí, 2007.

MUENCHEN, C. A disseminação dos Três Momentos Pedagógicos: um estudo sobre práticas docentes na região de Santa Maria/RS. Florianópolis: UFSC, 2010. 273 p. Tese (doutorado) - Programa de Pós-Graduação em 
Educação Científica e Tecnológica, Universidade Federal de Santa Catarina, Florianópolis, 2010.

MUENCHEN, C. DELIZOICOV, D. Concepções sobre Problematização na Educação em Ciências. Enseñanza de las Ciencias, v. 1, p. 2447-2451, 2013.

MUENCHEN, C., DELIZOICOV D. Os três momentos pedagógicos e o contexto de produção do livro "Física". Ciênc. Educ. Bauru, v. 20, n. 3, p. 617-638, 2014.

MUENCHEN, C., DELIZOICOV, D. PESQUISAS EM EDUCAÇÃO EM CIÊNCIAS NA REGIÃO DE SANTA MARIA/RS: ALGUMAS CARACTERÍSTICAS. VII Encontro Nacional de Pesquisa em Educação em Ciências (ENPC). Florianópolis, SC, 2009.

MUENCHEN, C.; DELIZOICOV, D. Práticas de Ensino de Ciências na região de Santa Maria/RS: algumas características. Revista Brasileira de Ensino de Ciência e Tecnologia, Ponta Grossa, v.3, n. 2, p. 47-65, mai./ago. 2010.
OlIVEIRA, et al. Cadeia Alimentar: modelos e modelizações no ensino de Ciências Naturais. IV Encontro Nacional de Pesquisa em Educação em Ciências (ENPEC), Bauru/São Paulo, 2003.

SAUERWEIN, I.; TERRAZZAN, E. A. A utilização do referencial teórico de Paulo Freire na compreensão de um processo de acompanhamento da prática pedagógica de professores de física. V Encontro Nacional em Educação em Ciências (ENPEC), Bauru/São Paulo, 2005.

SOLINO, A. P., GEHLEN, S. T. A contextualização na Abordagem Temática Freireana Ensino de Ciências por Investigação. IX Encontro Nacional de Pesquisa em Educação em Ciências (ENPEC), Águas de Lindóia/São Paulo, 2013 